\title{
Can painting human cells with exogenous maltoporin enable efficient therapeutic gene transfer by bacteriophage lambda vectors?
}

\author{
Oleg Tolmachov \\ National Heart and Lung Institute \\ Imperial College London \\ Sir Alexander Fleming Building, Exhibition Road \\ London, United Kingdom \\ E-mail o.tolmachov@imperial.ac.uk
}

\begin{abstract}
Many gene therapy strategies require transfer of highmolecular weight DNA into human cells. To enable clinical trials, these vectors need to be produced on a large scale and at low cost. The production of effective high-capacity vectors like HSV-amplicons and helperdependent adenoviral vectors is difficult to up-scale, so new inexpensive vectors are needed for the efficient delivery of high-molecular weight DNA to human cells. Bacteriophage lambda vectors can accommodate up to about $46 \mathrm{~kb}$ of therapeutic DNA and can be easily produced in an industrial setting. However, the lambda vectors transfer DNA into mammalian cells with only a low efficiency. It was shown that bacteriophage lambda virions ejected their DNA in the presence of the purified receptor for bacteriophage lambda, maltoporin (LamB protein), encoded by the malB gene of Shigella sonnei 3070. This property of $S$. sonnei maltoporin was exploited for the bacteriophage injection-driven DNA loading of liposomes and other polymer nanocontainers displaying maltoporin. Relying on the above evidence I hypothesize that the efficient gene transfer by industrially produced bacteriophage lambda vector virions, such as cosmid transducing particles, to human cells can be accomplished after incorporation (protein painting) of the purified $S$. sonnei maltoporin into the human plasma membrane.
\end{abstract}

\section{Background}

Gene therapy strategies involving delivery of large therapeutic cDNAs or large cell-specific promoters require vectors capable of efficient transfer of high-molecular weight DNA to human cells (Hibbitt et al. 2007). To enable gene therapy clinical trials, these vectors need to be produced on a large scale and at low cost. However, effective high-capacity gene vectors such as helperdependent adenoviral vectors and HSV-amplicons are cumbersome to manufacture, especially when a large vector output is required (Palmer and Ng, 2003; Zaupa et al.

2003). Therefore, there is a need for new methods of gene delivery that can allow efficient transfer of high molecular weight DNA to human cells with inexpensive gene vectors generated in an industrial setting.
Gene vectors based on bacterial viruses, bacteriophages, can package up to about $170 \mathrm{~kb}$ of double stranded DNA and are easily produced on a large scale. However, bacteriophage vectors require bacterial receptors to deliver their genetic cargo into the cells and so can mediate genetic transfer to mammalian cells with only a low efficiency (Volcy and Dewhurst, 2009). One of the best-studied bacteriophages is bacteriophage lambda of Enterobacteriaceae which injects its DNA into recipient cells after attachment to its cognate bacterial receptor maltoporin (LamB protein). The bacteriophage lambda genome size is $48.5 \mathrm{~kb}$, which sets the maximum capacity of stable lambda vectors for therapeutic DNA at about 46 kb. It was shown that bacteriophage lambda particles ejected their DNA in the presence of the purified maltoporin receptor, encoded by the malB gene of Shigella sonnei 3070, while maltoporin of Escherichia coli was not sufficient for DNA ejection without addition of toxic organic solvents (Roessner et al. 1983; Roessner and Ihler, 1987). This property of maltoporin from $S$. sonnei was exploited for bacteriophage injection-driven DNA loading of liposomes and other polymer nanocontainers displaying maltoporin (Roessner et al. 1983; Roessner and Ihler, 1987; Graff et al. 2002). It is a straightforward assumption that therapeutic liposomal gene vectors can be produced by injecting therapeutic DNA into liposomes using purified bacteriophage lambda transducing particles, that is, lambda virions containing non-lambda DNA (Roessner et al. 1983; Lambert and Rigaud, 2003). Both replication-competent lambda vectors and cosmids, bearing just a small fragment of the lambda genome with the lambda's packaging sequence, can be considered for injection-driven DNA entrapment in the liposomal vectors.

Injection-assisted DNA loading of maltoporin-bearing liposomes using bacteriophage lambda virions occurs via a process that does not precisely coincide with the mechanism existing in vivo during bacteriophage infection of bacteria (Esquinas-Rychen and Erni, 2001). Notably, in vivo bacteriophage lambda DNA injection is always complete, while intra-liposomal injections can be occasionally only partial (Roessner et al. 1983). Reproducible complete ejection of DNA from bacteriophage particles can be achieved by the addition of polycations to the interior compartment of the 
proteoliposomes (Lambert and Rigaud, 2003) with polycations likely to be providing a pulling force for the entering negatively charged DNA (Inamdar et al. 2006). However, the employment of polycations in therapeutic applications can be undesirable because they are often toxic (Hunter 2006). In addition, in comparison to existing methods of DNA entrapment within liposomes (Szelei and Duda, 1989; Fenske and Cullis, 2005), bacteriophage injection-driven liposome loading appears fairly cumbersome. So far it was never used to prepare of liposomal vectors with a therapeutic genetic cargo.

Clearly, instead of reconstitution in the liposomal membranes, purified maltoporin can be directly used to furnish the plasma membrane of target human cells destined for therapeutic gene transfer with bacteriophage lambda transducing particles. Efficient incorporation of exogenous integral and GPI-anchored proteins into mammalian cells (so-called 'cell painting') was previously described with the proteins being solubilised and delivered to the plasma membrane in a lipid carrier or a conventional mild detergent (Premkumar et al. 2001; Liu et al. 2007).

\section{The hypothesis}

Relying on the evidence showing injection-driven DNA transfer by bacteriophage lambda virions into liposomes bearing maltoporin receptor from $S$. sonnei 3070, I hypothesize that efficient gene transfer by the bacteriophage lambda vector virions, such as cosmid transducing particles, into human cells can be accomplished after painting of the cells with the purified $S$. sonnei maltoporin. Transduction of maltoporin-painted human cells by the DNA-ejecting lambda vector particles can be an efficient and up-scalable method for delivery of high molecular weight therapeutic DNA.

\section{Evaluation of the hypothesis}

In general, gene therapy can be performed in vivo and $e x$ vivo. Genetic treatment in vivo involves direct administration of the gene vector to a patient. Ex vivo gene therapy consists of taking a biopsy from a patient, genetically modifying the cells in vitro and then transplanting the modified cells back to the patient. It might be a challenge to confirm the hypothesis in a multi-factored scenario of in vivo gene delivery. Therefore, the proposed gene transfer strategy should be initially tested in an ex vivo gene therapy setting with better control of the transduction environment in vitro. Transplantation of primary human fibroblasts after genetic modification ex vivo can be used as a treatment for a number of neurodegenerative and other diseases (Tuszynski et al. 2005). Primary fibroblasts are also simple to grow and, thus, can be used as a model cell population to evaluate the efficiency of the maltoporin painting and subsequent lambda-mediated gene delivery.

A straightforward way to produce $S$. sonnei maltoporin is by its overexpression in a non-pathogenic host such as $E$. coli K12 harbouring a deletion of its own malB gene (Roessner et al. 1983). LamB is an integral membrane protein and its solubilization can be achieved by using sodium cholate, other mild detergents like Triton ${ }^{\circledR}$ X-100 or possibly lysophosphatidylcholine, a known carrier of integral membrane proteins for their efficient incorporation into the cellular plasma membrane (Premkumar et al. 2001).

The cells to undergo genetic treatment are to be furnished with maltoporin from $S$. sonnei with the excess maltoporin thoroughly removed by washing the cells. Maltoporin is likely to be inserted into the plasma membrane in various conformations with only one conformation being a correctly exposed bacteriophage lambda receptor. Maltoporin-painted cells should be incubated with purified bacteriophage lambda vector particles containing therapeutic or marker DNA and the efficiency of gene transfer should be evaluated by standard methods relying on the transgene expression in the treated cells.

Bacteriophages are known for their ability to pester industrial bacterial fermentations and so, turning misfortune into a blessing, the manufacture of replication competent bacteriophage lambda vectors on a large scale is a straightforward process. Non-replicating lambda transducing particles can be produced by cosmid packaging in vitro using purified proheads, tails and terminase. A single-strain system for the generation of lambda packaging extract was described by Rosenberg et al. (1985) with inducible phage functions being born on a cos-less helper prophage (Rosenberg et al. 1985). This strain can be adapted for a mass scale in vivo packaging of cosmid DNA in industrial fermenters.

The injection of therapeutic DNA by the lambda vector particles into human cells can be complete, perhaps due to the DNA binding factors in the cytoplasm generating a pulling force on the DNA being ejected from the lambda capsids (Inamdar et al. 2006). There might be some differences in the repertoire of the DNA binding factors between various human cell types resulting in a cellspecific variation of the efficiency of lambda injectionmediated gene transfer.

Lambda transducing particles inject into the recipient cells linear double stranded DNA with complementary 12-base single-stranded overhangs (cohesive ends). The linear status of the delivered DNA is compatible with the efficient gene transfer into mammalian cells (Hirata et al. 2007). If ligated in human cells, the cohesive ends might enable circularisation of the transferred DNA and its subsequent replication driven by the Epstein-Barr oriP-EBNA1 module or other replicons from circular episomes.

Mutant versions of the maltoporin receptor, which are better adapted to the milieu of the mammalian plasma membrane, can be obtained by directed evolution strategies. In addition, therapeutic lambda virions can be improved by 
a capsid display of cell-targeting ligands (Zanghi et al. 2007) and protein moieties mediating evasion of the immune system.

\section{REFERENCES}

ESQUINAS-RYCHEN, Margarita and ERNI, Bernhard. Facilitation of bacteriophage lambda DNA injection by inner membrane proteins of the bacterial phosphoenolpyruvate: carbohydrate phosphotransferase system (PTS). Journal of Molecular Microbiology and Biotechnology, July 2001, vol. 3, no. 3, p. 361-370.

FENSKE, D.B. and CULLIS, P.R. Entrapment of small molecules and nucleic acid-based drugs in liposomes. Methods in Enzymology, February 2005, vol. 391, p. 7-40.

GRAFF, A.; SAUER, M.; VAN GELDER, P. and MEIER, W. Virus-assisted loading of polymer nanocontainer. Proceedings of the National Academy of Sciences of the United States of America, April 2002, vol. 99, no. 8, p. 5064-5068.

HIBBITT, Olivia C.; HARBOTTLE, Richard P.; WADDINGTON, Simon N.; BURSILL, Christine A.; COUTELLE, Charles; CHANNON, Keith M. and WADEMARTINS, Richard. Delivery and long-term expression of a $135 \mathrm{~kb}$ LDLR genomic DNA locus in vivo by hydrodynamic tail vein injection. The Journal of Gene Medicine, June 2007, vol. 9, no. 6, p. 488-497.

HIRATA, Kazuhiro; NISHIKAWA, Makiya; KOBAYASHI, Naoki; TAKAHASHI, Yuki and TAKAKURA, Yoshinobu. Design of PCR-amplified DNA fragments for in vivo gene delivery: size-dependency on stability and transgene expression. Journal of Pharmaceutical Sciences, September 2007, vol. 96, no. 9, p. 2251-2261.

HUNTER, A. Christy. Molecular hurdles in polyfectin design and mechanistic background to polycation induced cytotoxicity. Advanced Drug Delivery Review, December 2006, vol. 58, no. 14, p. 1523-1531.

INAMDAR, Mandar M.; GELBART, William M. and PHILLIPS, Rob. Dynamics of DNA ejection from bacteriophage. Biophysical Journal, July 2006, vol. 91, no. 2, p. 411-420.

LAMBERT, Olivier and RIGAUD, Jean-Louis. Phage DNA transfer into liposomes. Methods in Enzymology, December 2003, vol. 373, p. 465-482.

LIU, Shanrong.; FOSTER, Barbara A.; CHEN, Tie; ZHENG, Guoxing and CHEN, Aoshuang. Modifying dendritic cells via protein transfer for antitumor therapeutics. Clinical Cancer Research, January 2007, vol. 13, no. 1, p. 283-291.

PALMER, Donna and NG, Philip. Improved system for helper-dependent adenoviral vector production. Molecular
Therapy, November 2003, vol. 8, no. 5, p. 846-852.

PREMKUMAR, Daniel R.D.; FUKUOKA, Yoshihiro; SEVLEVER, Daniel, BRUNSCHWIG, Elaine; ROSENBERRY, Terrone L.; TYKOCINSKI, Mark L. and MEDOF, M. Edward. Properties of exogenously added GPI-anchored proteins following their incorporation into cells. Journal of Cellular Biochemistry, 2001, vol. 82, no. 2, p. 234-245.

ROESSNER, Charles A. and IHLER, Garret M. Sequence of amino acids in lamB responsible for spontaneous ejection of bacteriophage lambda DNA. Journal of Molecular Biology, June 1987, vol. 195, no. 4, p. 963-966.

ROESSNER, Charles A.; STRUCK, Douglas K. and IHLER, Garret M. Injection of DNA into liposomes by bacteriophage lambda. The Journal of Biological Chemistry, January 1983, vol. 258, no. 1, p. 643-648.

ROSENBERG, Susan M.; STAHL, Mary M.; KOBAYASHI, Ichizo and STAHL, Franklin W. Improved in vitro packaging of coliphage lambda DNA: a one-strain system free from endogenous phage. Gene, February 1985, vol. 38, no. 1-3, p. 165-175.

SZELEI, Jószef. and DUDA, Ernö. Entrapment of highmolecular-mass DNA molecules in liposomes for the genetic transformation of animal cells. Biochemical Journal, April 1989, vol. 259, no. 2, p. 549-553.

TUSZYNSKI, Mark H.; THAL, Leon; PAY, Mary; SALMON, David P.; SANG, U. Hoi; BAKAY, Roy; PATEL, Piyush; BLESCH, Armin; VAHLSING, H. Lee; HO, Gilbert; TONG, Gang; POTKIN, Steven G.; FALLON, James; HANSEN, Lawrence; MUFSON, Elliott J.; KORDOWER, Jeffrey H.; GALL, Christine and CONNER, James. A phase 1 clinical trial of nerve growth factor gene therapy for Alzheimer disease. Nature Medicine, May 2005, vol. 11, no. 5, p. 551-555.

VOLCY, Ketna and DEWHURST, Stephen. Proteasome inhibitors enhance bacteriophage lambda (lambda) mediated gene transfer in mammalian cells. Virology, February 2009, vol. 384, no. 1, p. 77-87.

ZANGHI, Christine N.; SAPINORO, Ramil; BRADELTRETHEWAY, Birgit and DEWHURST, Stephen. A tractable method for simultaneous modifications to the head and tail of bacteriophage lambda and its application to enhancing phage-mediated gene delivery. Nucleic Acids Research, February 2007, vol. 35, no. 8, p. e59.

ZAUPA, C., Revol-Guyot, V. and EPSTEIN, A.L. Improved packaging system for generation of high-level noncytotoxic HSV-1 amplicon vectors using Cre-loxP sitespecific recombination to delete the packaging signals of defective helper genomes. Human Gene Therapy, July 2003, vol. 14, no. 11, p. 1049-1063. 